\title{
Ethnologies
}

\section{Stand-up Comedy as a Genre of Intimacy}

\section{Ian Brodie}

Volume 30, numéro 2, 2008

Hommage à Peter Narváez

In Honour of Peter Narváez

URI : https://id.erudit.org/iderudit/019950ar

DOI : https://doi.org/10.7202/019950ar

Aller au sommaire du numéro

\section{Éditeur(s)}

Association Canadienne d'Ethnologie et de Folklore

ISSN

1481-5974 (imprimé)

1708-0401 (numérique)

Découvrir la revue

Citer cet article

Brodie, I. (2008). Stand-up Comedy as a Genre of Intimacy. Ethnologies, 30(2), 153-180. https://doi.org/10.7202/019950ar

\section{Résumé de l'article}

En se servant de l'amplification, les monologuistes humoristiques réussissent à créer une réaction naturelle de la part du public, en employant les modes du discours quotidien, interpersonnel, celui de la conversation, évitant ainsi dans la majeure partie des cas la distanciation requise par la plupart des formes de représentation culturelle. En maintenant le contrôle de cette conversation, ils peuvent paradoxalement l'abandonner et le reprendre quand il le faut, créant ainsi l'illusion d'un rapport d'intimité, d'échange et de réciprocité entre le public et eux-mêmes. Cet article pose les premiers jalons d'un cadre permettant de comprendre le monologue humoristique dans la relation qu'il entretient avec les genres folkloristiques en considérant en premier lieu l'intimité et non l'humour.
Ce document est protégé par la loi sur le droit d'auteur. L'utilisation des services d'Érudit (y compris la reproduction) est assujettie à sa politique d'utilisation que vous pouvez consulter en ligne.

https://apropos.erudit.org/fr/usagers/politique-dutilisation/ 


\title{
Stand-up Comedy as a Genre of Intimacy
}

\author{
Ian Brocie \\ CapeBreton University
}

To state the obvious, stand-up comedy ${ }^{1}$ is a form of talk. It implies a context that allows for reaction, participation, and engagement on the part of those to whom the stand-up comedian is speaking. When it is mediated through broadcasting and recording, an audience present to the performer is included in that mediation. However heavily one-

1. [It would be far simpler and efficient to enumerate the ways in which Peter $\mathrm{N}$ arváez has not influenced both this article in particular and my folkloristic training in general. In addition to him being my erstwhile thesis advisor, even the most obtuse reader (of which Ethnologies has none) will note $\mathrm{N}$ arváezarian moments in what follows: most notably the continuum of popular culture and folklore ( $N$ arváez and Laba 1986) and the interpenetration of one into the other, but also the myth of acousticity (2001), the paradox of certain forms of humour on certain subject-clusters (2003), and the emancipation within folklore of the term "vernacular" from the confines of architecture (1984; 1995). O ur points of divergence (not simply my use of parentheticals - and em dashes - within formal writing) are no doubt what will lead to my demise. Much congratulation and love to a man I am lucky to call my teacher and proud to call my friend].

Michael Stebbins cites the ninth edition of W ebster's Collegiate Dictionary and designates the origin of the term at 1966 (1990: 5), while John Limon, without citation, assigns it to "in or around the year of Lenny Bruce's death," again 1966 (2000: 126). But in $1962 \mathrm{G}$ eorge $\mathrm{C}$ arlin referred to "the stand-ups" to designate an older form of comedian, different from contemporary performers like M ort Sahl, during an appearance on the television show Talent Scouts: "T here are thousand of comedians in this country, but basically only two types of humour: there's the old school, and the new school. I think we recognise them both. The old school is largely made up of the fast-paced stand-up comedians, the oneliner comics who came from vaudeville and burlesque, and they comprise the insult school of humour" (archival footage in Carlin 1997). 
sided, it is nevertheless a dialogic form, performed not to but with an audience. $^{2}$

W hen the stand-up speaks, the text could be seen as a collection of smaller textual units, many of which are identifiably analogous to classic folkloric genres - riddles, jokes, legends, tall tales, toasts, dozens, dites, memorates, blasons populaires, and so forth - or to forms of rhetoric and polemic (see M intz [1985] 1998; Zolten 1993). H owever, the standup performance is more than a mere collection of items; it is a contiguous entity. To divorce the stand-up text from the context and texture of performance (Dundes 1964) - as stand-ups themselves do when repackaging their work in book form (DeG eneres 1995; Rock 1997) - raises the problem of de-contextualisation critiqued by folklorists concerned with holistic understandings of performance. For example, legends, like stand-up comedy, are exchanges and negotiations within small groups. Just as recent works on legend (e.g. Dégh 2001; Ellis 2001) underline the importance of recording and studying legends in context, so too must any study of stand-up comedy consider not only the verbal text but also its performance context, and the intentional adaptation by the performer for subsequent mediations.

\section{Genre Problems}

The purpose - if not the function (Bascom 1954: 343) - of standup is entertainment; as verbal play, it utilises humour. Countless theorists (Bergson 1900; Freud [1905] 1976; Lonergan 1957; O ring 1992) identify the phenomenon of the humorous as the revelation of (by the performer) or a reaction to (by audiences) a physical, intellectual, social, moral, or emotional incongruity, which could just as easily elicit feelings of terror. W hat critics often leave unsaid is that the identification of the incongruous implies a more or less shared worldview. Much as those engaged in legend telling are negotiating an underlying truth proposition (e.g. Dégh 2001; Ellis 2001), so too do the stand-up and her audience negotiate a claim of incongruity.

2. Emerging from my ongoing dissertation work, I originally presented this paper with the title "Stand-up C omedy and/as Legend-Telling" at the $25^{\text {th }}$ Perspectives on Contemporary Legends C onference, Logan, U tah, in M ay 2007. M y thanks go to the participants of that conference, notably Diane Goldstein, Jon Lee, Jodi M cDavid, Lynne M cN eill, and Robin Parent; Martin Lovelace, then head of the Department of Folklore at M emorial U niversity of $\mathrm{N}$ ewfoundland; A rthur Tucker, Dean of the School of A rts and Community Studies at Cape Breton U niversity; and SSHRC. 
Simultaneously, there is a negotiation of the appropriate response to the incongruity: of the interwoven nexus of commonly held assumptions that constitutes the worldview of the group. The more the assumption is exposed as incongruous, the more the reaction elicited can be terror or grief instead of laughter. Lastly, the stand-up is in a position of re-affirming her right to be the one to reveal this incongruity: that she is not making an outsider's pronouncement and judgment but knows whereof she speaks as a member of this particular folk group. This negotiation is a continuous process with the specific audience to which she is performing, and thus the stand-up performance is a collaborative act.

This theoretical perspective resembles that standard distinction in introduction to folk literature courses, drawing on William Bascom's distinction between myth, $M$ ärchen, and legend (1965) before loading it down with qualifications and caveats. Both $M$ ärchen and myth are public genres. The privilege and/or responsibility of their narration is accorded to particular a priori statused members of the group. Their content is performed largely uncontested: $M$ ärchen by virtue of it being understood as fiction (and thus to contest its veracity is redundant), and myth by virtue of it being understood as sacredly true (and thus to contest its veracity is anathema).

W hereas $M$ ärchen and myth are largely public and exhortatory, legends are private and interpersonal: they imply an underlying truth proposition, and they become opportunities for its negotiation. A s Bill Ellis $(2001: 22,60)$ has shown, legends told in context are collaborative texts, wherein the principal performer builds the narrative through the reactions of the listener, such as indications of belief and disbelief, requests for clarification, or corroboration through the presentation of similar evidence or parallels. Legends do not provide their own resolutions, as they end in disequilibrium: the participants in the legendtelling event provide the resolution through a subsequent, extranarrative commentary.

Jokes likewise do not provide their own resolution. The listener restores equilibrium by "getting it": recognising the vector the narrative should have taken had it unfolded according to expectations, contrasting that against how it did unfold, and grasping the proposition one must admit to shift the former to the latter. This proposition is typically what G ary Butler (1991) refers to as a "traditum," a statement of belief which is not necessarily believed but is widely known to the group in which 
the joke is performed: the "nature" of blondes, A ggies, M ainlanders, etc. (cf. Davies 1990; H enken 2006; Thomas 1997). "G etting it" differs from "finding it funny": the former is noetic, a consequence of understanding; the latter psychic, a consequence of affective resonance. There is a mutual mediation between the two, but one can examine each one apart from the other.

Jokes differ from legend largely in how one frames them: narrative cues and the context in which jokes arise typically indicate that the narrator means the listener to understand jokes as play and not legend's serious talk. Elissa Henken (2006) demonstrated the ease with which the same basic narrative can shift (or be shifted) from legend to joke in her study of interuniversity blasons populaires. Both are predicated on the same set of assumptions, but whereas the proposition of legend is of historical, sociological, psychological, or theological import, the proposition of the joke is a conceit, adherence to which need not extend beyond the play frame.

A Iready I may appear to have introduced a contradiction. On one hand I speak of the distinction between legend-telling, which is dialogic, and myth or $\mathrm{M}$ ärchen-telling, which is monologic. The latter takes place upon the stage (in Erving Goffman's [1959] use of the term) with a sharp distinction - both physical and performative - between teller and listener, the former in the backstage or offstage, where distinctions between them are more or less rendered null. Yet stand-up is obviously performed upon a stage, and both teller and listener expect and maintain an analogous formalised distinction between them. My premise is that one of the characteristics of stand-up comedy, and one of the hallmarks of stand-up as a performative genre, is how it tends to be predicated on the illusion of intimacy ( $N$ arváez 2001), a disregard for the distancing of the stage. A nd it performs this move through a variety of techniques.

\section{Microphone Fiends}

W hile stand-up ${ }^{3}$ comedy may be the inheritor of a variety of vernacular traditions and products of popular culture, it is a medium

3. O ne of my very helpful and kind anonymous readers encouraged me to qualify this use of stand-up with the adjective "contemporary:" however, the thrust of my argument turns on stand-up comedy emerging from the presence of the 
that cannot exist without technological advances. Though stand-up comedy draws on a number of features (see inter alia Fulton 2004; Koziski 1984; M intz [1985] 1995; Price 1998), what distinguishes it as a whole from other forms of verbal comedy, and where one can deduce its origins, is the advanced use of the microphone.

$W$ ith respect to the effect of the microphone, scholarship has most closely scrutinised singing. Robert $\mathrm{O}$ 'M eally notes that Billie Holiday, "whether in clubs or on recording dates, ... continued to deliver her lyrics as if only for one or two listeners whom she addressed face to face" (1991: 32). Simon Frith indicates how "the microphone allowed us to hear people in ways that normally implied intimacy - the whisper, the caress, the murmur" (1996: 187). Roy Shuker summarises the affect of microphones by describing how it "revolutionised the practice of popular singing, as vocalists could now address listeners with unprecedented intimacy" (2001: 52). Paula Lockheart writes that with a microphone, in both broadcasting and live performance, "the volume, pitch range, and vocal production of both the men and the women became closer to that of their conversational speech, and the presentation of text became more like that of conversational A merican English in pronunciation and phrasing" (2003: 380). John Szwed draws comparisons between M iles Davis' use of the microphone, Frank Sinatra's, and Konstantin Stanislavsky's:

W ith a microphone, singers and musicians could join the new naturalistic stage rhetoric that was developing in the wake of the Russian director Stanislavsky's plea that actors should cease portraying emotions to the audience and begin communicating them directly. In the same era when audiences were becoming accustomed to closer and more intimate looks at actors on film, the mike removed the need

microphone. The point is, I feel, more than semantic: for stand-up's purported function as either cultural anthropology (Koziski 1984) or social mediation (M intz [1985] 1998), antecedents and forebears are suggested ranging from the court jester to M ark Twain and Will Rogers. Such suggestions of ancestry are not without merits, but as a form or, more precisely, as an emic genre with an attendant set of expectations, including the dialogic properties outlined throughout this article, stand-up comedy, contemporary or otherwise, does not exist without amplification. 
for musicians and singers to struggle to close the physical distance between themselves and the audience (2002:188).

Kate $A$ ugestad ${ }^{4}$ likewise notes the cross-over between naturalistic speech and singing:

The microphone invited a different way of pronouncing the words, a more clear diction and a new singing style that came to reflect the vernacular of everyday-like speech. M icrophonic singing enabled a speechlike voice production to be used.... Singing that comes close to speaking seems to signal something popular, something trustworthy, something everyday-like. O ne often sees that the most popular singers are those who manage to combine a speech-like way of singing with a kind of natural, but subdued virtuosity, in an easy recognisable form of competence that still comes forward as something extraordinary in its ordinariness (2004: 46-48, emphasis in original).

The spoken word has similarly been studied in terms of amplification. A manda Dargan and Steve Zeitlin in their work on street vendors write how, "[t]oday many market vendors use microphones which make rhythm and rhyme more important than the use of falsetto and vowel sounds to throw the voice" (1983: 6). Both Lockheart (2003) and Peter N arváez (1986) have written on the use of the microphone by politicians to create an "intimate" connection: Lockheart on the "Fireside chats" of Franklin Delano Roosevelt, and $\mathrm{N}$ arváez on $\mathrm{N}$ ewfoundland politician Joey Smallwood and his ability to address a crowd through a public address system based on his experience as a broadcaster.

N evertheless, not much is written, all told, on the microphone and/ or amplification within the context of live performance. The emphasis is typically on either recording or broadcasting. O ne of the principal points made about the use of the microphone is that, through projecting the human voice at its natural register - either through space in the case of live broadcasting or through time and space through recordings or the broadcasting thereof - an illusion of intimacy can be created despite space/time distances. Scholars only allude to how this restoration of intimacy is also possible in large-scale theatre contexts. A performer can make herself heard within a room without recourse to shouting: she can talk in a manner commensurate with one-on-one communication.

4. I am very grateful to another anonymous reader for directing me to this reference. 
Simply put, a microphone, as part of an amplification system, allows the human voice to transcend the acoustic limitations of physical space. The medium of the microphone, therefore, not only alters the stand-up performance but also allows for new expressive forms to take place on the stage. A s such, it changes the nature of what one says and how one says it.

A s A llison McCracken wrote about crooners, they "not only did not project their voices in traditional ways, but they also chatted with their listeners; they created an identifiable personality" (1999: 392). Similarly, the use of amplification allowed for comic performances that did not rely solely on the natural human voice to be heard above a crowd. Short one-liners could give way to longer pieces. W hispers, mutterings, and going off on tangents - moments at which an unamplified voice could lose the focus of the crowd and control of the situation - become possible again. A patter could be built up which was not simply a stream of jokes but an interplay of genres. The reaction garnered from the crowd did not need to be exclusively laughter: a proposition could be put forth, which could elicit a reaction from the crowd, which could then in turn be developed and defended. The comedy performance thus became a creation of both performer and the audience.

DoVeanna Fulton alludes to this collaboration between comedian and audience with respect to the performances on D ef Comedy Jam, a series produced by Russell Simmons of D ef Jam Records and originally broadcast on HBO.

The stage is set very close to the audience so that comics are neither at a distance from nor at an exaggerated level above them. This setting engenders a sense of community and familiarity.... This setting allows for the comics to carry on a dialogue with the audience. Comedians often ask questions of the audience, and the answers are heard by nearly everyone. This dialogue is a form of A frican A merican oral tradition of call and response, which is quite different from the hecklers mainstream comedians may encounter (2004: 87-88).

$\mathrm{H}$ owever much voice is given to the audience, the comedian always has more tools at her disposal to wrest control back, should that be required. This newly available intimacy between performer and audience lacks the exclusive unidirectionality of a broadcast or a recording, where the audience may be an active or passive listener but 
can not alter the performance. But neither is there the potential for the switching of assumed identities of performer and audience member that Robert Georges suggests can characterise storytelling events (1969).

In the relationship between performer and audience, power resides with the performer. Deborah Wong makes a similar argument in her discussion of a Vietnamese-A merican rapper:

\begin{abstract}
$\mathrm{H}$ is rap is emphatically about the eye/l, the process of defining a self. In performance, his hands are constantly in motion; one grips the defining microphone, the other points again and again to himself: I have the microphone, I'm an A sian.... But this is of course only half of the dynamic. A s often as he gestures toward himself, redefining and positioning himself, he then points to the audience - the defining listener (Wong 1994:164, emphasis in original).
\end{abstract}

But the amplified performer's voice literally overpowers that of any one member of the audience. Wong goes on to make this same point concerning the general allure of karaoke among A sian and subsequently A sian-A merican populations. The use of the microphone makes the control over artistic production, even mimetic performance, explicit. The more the audience operates as a collective, the less it can articulate its position with any precision or nuance. The microphone, in conjunction with the stage, allows the performer to control the situation by continually drawing focus to herself.

So, if one imagines a continuum, with a purely monologic, unidirectional communication at one end, and a purely dialogic, bidirectional communication at the other, stand-up resides somewhere in the middle, with individual styles resting along a broad spectrum. ${ }^{5}$

\title{
Not "jokes" but "Bits" and "Routines"
}

W hat do amplification and the attendant intimacy do to the performed text? Imagine two rooms: each is a large club or a small theatre with an audience of about 200 people. Likely, there is alcohol

5. By "dialogic" I wish to explicitly refer to stand-up being a production of two (or more) parties: performer and audience(s). I am not using it here in the same sense as M ikhail Bakhtin (in his sense of the novel being fundamentally different from other genres by virtue of it being written in the vernacular, incorporating a variety of genres and the various languages appropriate to each [1981: 412]), although it does not exclude that sense, as the performance is both literally and figuratively a dialogue. 
flowing, either prior to or during the performance, with a consequent relaxation of some social constraints. In both of these rooms, the person talking onstage may be one of a number of performers, each with her own appropriate set of responses. She is framed as being funny: the audiences in both scenarios have the expectation or the "right" (G eorges 1969: 319) of being entertained, and their "responsibility" (319) is to react, with laughter being the reaction most sought by the performer.

The difference between the first and second rooms is amplification. In the first, in order to maintain the balance of the exchange, and to keep focus, the comedian must contend with the possibility of the audience overwhelming her. Pauses, rhetorical questions, digressions, diversions, distractions, and long descriptive passages all are opportunities for the audience to react in an unanticipated manner and to shift (or pull) focus away from the performer. A nd the sheer act of projecting - talking loudly or shouting, one person talking against two hundred - negates much in the way of subtlety of intonation and the texture of performance.

In the second room, the performer has a microphone. To be heard, she must merely speak, and her voice can become as loud as the entire audience's combined. Her speech more closely resembles everyday speech - far more, at least, than the shouter's. Because of the power accorded the performer through amplification, the possibility of allowing all those previously unavailable elements emerges. In other words, knowing that one can easily pull focus back gives license for giving it away. The microphone helps to create the illusion of a small group discussion irrespective of the group's actual size. ${ }^{6}$

The performer in the first scenario, to maintain the focus of the large crowd, has to perform her text without interruption, pausing only at its completion for laughter. The text has an uninterrupted flow, with

6. But to qualify this, during the British alternative comedy movement of the late 1970 s and early 1980s, a form of comedy emerged within a punk aesthetic in reaction to both an $0 x$ bridge-centered intellectual comic tradition and working-class pub comedy (which was known for its prevalent sexism and racism). A s befits its anarchic roots, the audience was notoriously antagonistic, particularly at the $C$ omedy Store club around which the movement was centered. Despite access to a microphone, Ben Elton developed a performance style in which he would not pause: "He realised that if you stand there, shouting, and without putting any pauses in, even pauses for laughter, then the chances of being heckled or being abused by the audience were reduced. So that's where he got his style from, to rant" (A ndy de La Tour, in W right 1999). 
a discernible beginning, middle, and end. There is an economy to the telling: the performer provides no description that does not contribute to the overall effect. The performer in the second scenario has a more languorous approach. She pauses for reactions of encouragement or discouragement, and is prompted into continuing, whether to justify what was just said or to build upon it. The audience, albeit as a largely undifferentiated entity, engages the performer: they are reactive, but not merely so. They are interactive.

O ne can frame this scenario alongside that of legend-telling. A frustration of legend research has been how texts have been rendered into discrete units, or "legend reports" as Ellis refers to them, through the practice of editing into neat packaged stories with a beginning, a middle, and (often, despite the disequilibrium feature) an end, either at the hands of a folklorist cum collector cum editor, or by a practiced storyteller. Stories are individuated, often extracted from their performative context by virtue of this stylistic re-rendering in which so much of the referential material is now contained and made explicit. There is a disassociation of the teller from the tale, in part conditioned by and conditioning the hoary old definition of legends as "regarded as true by the narrator and his audience" (Bascom 1965: 4). The legend, as opposed to the legend report, is a communication that depends on an overlapping worldview and builds on shared understanding. It is a narrative in embryonic form, woven around assumptions that the teller introduces or reintroduces, and that the participants' interpretation tests, exemplifies, and proofs. It arises in the flow of discourse and submerges again without recognition of its (generic) presence.

Jokes, like legend reports, tend to be self-contained, discrete units. One can understand them, for the most part, outside of their performance contexts (which is not to say that one will necessarily find them funny or appreciate them). Unlike legend reports, such self-containment is not the consequence of questionable collectors and emendations, as legend reports: joke-telling is framed much like $\mathrm{M}$ ärchen- or mythtelling: a listener gives focus to the teller until the completion of the narrative. In joke-telling sessions, the performer role might switch between jokes, this switch might be rapid and frequent, and one joke might lead to another one of a similar type or content, but the narratives are isolatable not simply by folklorists, but by the participants themselves. Such jokes tend to be akin to those types told by performers in the non-amplified room. 
Stand-up comedians do not, as a matter of course, tell jokes in the sense of a series discrete units, with an explicit set-up which culminates in a punch line. Instead, they interweave material into a routine, which may run from five minutes to over two hours. Each unit, or "bit," is inexorably linked with the others in the routine, the performance venue, composition of the audience, the perceived relationship between the teller and the audience, the technological medium (beyond amplification) in which it is being transmitted, and the personality of the comedian herself.

O ne could suggest that a joke is precisely that form of humorous narrative that can be - and is - abstracted from its original performance context. W hat makes a joke a joke, in other words, is that the listener (and the collector) can make it wholly independent from a specific performer and treat it as an isolatable or discrete unit. It is not based in personal but in collective worldview. Were one to incorporate wholesale someone else's joke into one's own repertoire, one would still need common ground with the original teller in order to effect a similar interpretation and reaction. The greater the manipulation required for the listener to abstract it, or the more inextricably the specific performer weaves it into their repertoire, the less one can successfully transfer it across repertoires. These bits sit nestled in the midst of a larger performance and are extracted only with difficulty. ${ }^{7}$ Thus bit is to joke as legend is to legend report.

Eddie Murphy makes this point explicitly in his stand-up concert Delirious from 1983. He is speaking to a young child in the audience, who M urphy imagines to have expected performances of his characters from Saturday N ight Live. The following section does double duty, as he notes how inextricable his material is from the flow of his entire performance, while what he says also serves as an illustration of an

7. O ne can also look at these bits much like formulae in an oral formulaic approach, where smaller units comprise the larger performance, and according to the immediate need, the performer can move these smaller units around or drop them entirely. W hen circumstances arise, the performer has in her repertoire "appropriate" formulae: interactions with anomalous and thus conspicuous members of the audience; putdowns for hecklers; covers for her own verbal or physical gaffes. 0 ne bit, especially one drawn from the repertoire as a response, can also initiate a chain of bits on a similar theme or of a similar style that comprise an unplanned routine. Spontaneous creation, however, is also a possibility, albeit often within the context of an established formulaic grammar. 
extract from a performance which is not - by most definitions of the word - a joke. It is also worth noting that the bit takes place within five minutes of the end of the performance, which allows for references to elements previously performed: ${ }^{8}$

\author{
I'm gonna tell y'all a little joke y'all can tell in school, alright? C ause \\ I've been telling this dirty stuff, okay? \\ H ere's a little joke for y'all. \{Turning to crowd at large\}Y'all can listen \\ to it too. [L] \\ Cause I know lots of times people see my show and then go to work \\ and try to tell my act and fuck my jokes up on the job and shit. [L] \\ They're like, \{in a Caucasian voice\} "A nd then he said 'Goonie- \\ googoo'! [L] \\ "A nd he had a G.I. Joe up his ass! [L] \\ "'H ey-hey-hey, I'm M r. T: I'll rip your cock off with my ass!'" [L] \\ A nd a dude will be standing, going, \{dry and sarcastic\} "Yeah, that's \\ very funny shit." (Murphy 1983: 1:02:23ff)
}

What is funny in performance - for the audience, at any rate does not translate well to the page, despite my efforts at transcription. Fortunately, the folklorist's job is not to transliterate verbal performance to text with an eye to keeping it as entertaining and commercially viable as it was originally. W hen comedians themselves engage in transposing their material to the page, however, such is their aim, and the result serves as further illustration. This is my transcription of a Chris Rock performance from his 1994 H BO special Big Ass Jokes.

8. To transcribe performances, I have been developing a system to indicate a variety of audience responses and to demonstrate performance rhythm. Bracketed characters ( $[L])$ indicate a reaction by the audience: $A=A$ pplause, $\mathrm{A} w=\mathrm{A}$ wing ( $\mathrm{a}$ sound of disappointment or sadness), $\mathrm{B}=\mathrm{B} 00 \mathrm{~s}, \mathrm{C}=\mathrm{C}$ heers, $\mathrm{H}=\mathrm{H}$ issing, $\mathrm{L}=\mathrm{L}$ aughter, $\mathrm{O}=\mathrm{O}$ oing (a sound of recognition of taboo topic), $\mathrm{S}=\mathrm{Silence}, \mathrm{W}=\mathrm{W}$ hooping. Colons $(:)$ indicate that more than one reaction is occurring simultaneously, while an arrow $(->)$ indicates transition from one to another. Words within angle brackets indicate discernible words from the audience $([<y e s>])$, within exclamation marks ([!no!]) indicates a single audience member's reaction, and a male or female symbol indicates a gendered reaction. Line breaks occur at prolonged pauses, audience interruptions, or to indicate the cadence of the line. Words in italics are specifically emphasised, underlined words indicates that the previous audience reaction is sustained but the performer is talking over or during it, and ellipses indicate false starts. The performer's gestures, stage directions, and other non-verbal cues are in curly brackets ( \{pointing upwards\}), and, when indicating tone or accent qualify the words following, which are in quotations. Ellipses in brackets on their own line indicate a non-transcribed section. 
A lright.

Things are going alright.

I can not complain.

Doing my special.

Doing a new movie.

$G$ ot a new TV show.

Successful black man. [A :C]

So you know, you know what's next, right?

W hite $\mathrm{G}$ irl. [L $->\mathrm{B}]$

$\mathrm{G}$ ot to get a white girl.

Can not be a successful black man without a white girl. [L]

They won't even let you buy a mansion without a white girl.

"H ere's a million dollars." \{nasal\} "W here's your white girl? [L]

"We have zoning restrictions." [L]

You know what's funny? You know what's funny? If you're black and you go out with a white girl, everything that goes wrong in your life people blame it on the white girl. [L]

Everything. It's like "Yo man, I heard C hris got hit by a bus."

"Fucking around with them white girls." [L]

"Yeah, I hear C hris broke his leg." "W hite girl. [L]

"T hat's what he gets."

People are bugged, man. There's like, you know, there's white girls who only go out with black guys. There's black girls who only go out with white guys. I met a black girl like that. Did not date black men. I said, "Girl, how come you don't date no black men?" She said, "N 0 reason.

"N 0 reason."

$\mathrm{No}$ reason?

So I punched her in the face. [L]

N ow she got a reason. [L] (Rock 1994:2:27ff)

It is the first bit of the performance. Rock anticipates and builds into the text the interaction with the audience, and the audience not only recognises his "successful black man" claim but praises it and reaffirms it. N ote also how the laughter following the "got to get a white girl" turns to (good-natured) dissent, in that the audience actively boos him. Of the entire routine, only the final bit about punching the woman approximates a joke inasmuch as it has a pattern of set-up and punch line that would not require much else to repeat, and can be easily amended to different contexts. This is the corresponding section from his book Rock This!:

Yes, things are going great. I do comedy specials. M ovies. A Ibums.

$\mathrm{G}$ ot a new TV show.

You know what's next? 
Right. W hite Girls.

$\mathrm{G}$ ot to get a white girl. You're not a successful black man without a white girl. They won't even let you buy a mansion without a white girl.

Black M an: Here's your million dollars.

R eal Estate A gent: W here's your white girl? W e have zoning restrictions. You know what's funny? If you're black and you go out with a white girl, everything that goes wrong in your life gets blamed on the white girl.

"H ey man, I hear C hris got hit by a bus."

"Going out with a white girl."

"Yeah, I hear Chris broke his leg."

"W hite girl. That's what he gets."

[... ]

People should date who they like. I believe in chemistry. If it works, go for it. But there are white girls who only go out with black guys.

A nd there are black girls who only go out with white guys.

[... ]

I once asked out a fine sister: she turned me down.

Her: Sorry. I don't date black men.

M e: G irl, how come you don't date black men?

$\mathrm{H}$ er: $\mathrm{N}$ o reason.

Me: No reason?

So I punched her in the face. N ow she's got a reason.

0 kay, I didn't really do that. I'm not really violent or intolerant (1997:107-108). ${ }^{9}$

Contrasting the performance with the version from the book highlights the absence of the qualifying "people should do what they like" preface to the seeming diatribe against miscegenation, and the need to qualify his most outrageous claim - the punching of the woman in the face - as an explicit fiction. In other words, the text requires the resolution, the return to equilibrium that - in performance - the audience provides with its laughter. The audience determines the alleged truth of the punching incident to be false, or, rather, fiction.

Ellen DeG eneres has also transliterated her routines into book form. O ne example appears in M y Point... A nd I Do Have O ne (1995):

I went camping recently for the first time. It was a fantastic experience.

I went to an amazing place: M ontana. I don't know of you've ever

9. I have rearranged the sections from the book to correspond with the order of the performance. 
been there, but it is gorgeous. I've never seen any place so spectacularly beautiful as M ontana. Or was it $M$ aine? It was $M$ aine. A nyway, it is beautiful, and I've never seen any place like it. It is so special.

The important thing is that I went camping. N ow, I normally don't wake up that early, but I woke up to watch the sun set. I was sitting in front of my tent, and eating breakfast - some type of Mueslix, or some other outdoorsy stuff, just eating it right from my hand. I didn't even have a bowl. I just had milk and the Mueslix and my hand.

A nyway, so I'm enjoying my M ueslix (that may be an exaggeration let's just say I was eating my M ueslix), when suddenly I hear some kind of noise. Since I'm alone in the middle of the woods, I'm a little bit scared. But I gather my courage, look up, and ... A www, how cute! O nly ten feet away from where I'm sitting there's a family of deer drinking from a little, babbling brook thing (I'm not sure of the technical outdoorsy term). Just the mother, father, and two little baby deer lit by the reddish glow of the setting sun. It was so beautiful, so perfect, so wonderful, and I thought "O h, I wish I had a gun." I could've just... BANG BANG BANG BANG BANG ! I could have shot 'em, gutted 'em, skinned 'em, then sprinkled 'em on my cereal.

A ctually, none of that story is true. W ell, some of it is true. I did go camping in Maine.

$\mathrm{N}$ o, that's not true either. The closest I've come to camping in M aine is spending a few nights at the Hilton in Maui (come to think of it, that's not very close). M y point ... and I do have one, is that I was being sarcastic. I don't understand hunting at all (1995: 145-46).

But this is how it was performed in a 1994 concert recording, released in 1996 on her Taste This CD (again in my transcription):

So, and, you know, I'm back on tour, which is fun, but I took a little time off between shooting the show and then coming out on tour. I went, um, camping, which was ... I hadn't ever done that ... which was an amazing experience. I went to an amazing place, which was ... M ontana. I don't know if anyone has been to M ontana, but ... [C: A ] It is gorgeous. I have never seen anything like it. A nd, um ... [bashful chuckle] I'm sorry. M aine. I was in M aine. [L] It is beautiful, and I've never seen any place like it. It is so special. A nyways, the story still applies. I'm camping, and ... [L] I woke up - and I never wake up this early - but I woke up to watch the sunset. I'm sitting in front of my tent ... [L] and, uh... 
I'm eating some, just, breakfast, some type of M ueslix or some kind of outdoorsy, just healthy and ... just from my hand, I didn't even have a bowl. I had milk ... [L]

and the M ueslix, and just a spoon made from wood. A nyways, so I'm [L]

I'm having my Mueslix and I hear some kind of noise, and of course I'm kind of scared, and I look, and, I'm telling you, like right, well like ten feet away from where I'm standing there is a family of deer drinking from a little babbling brook thing that was there. Just a mother, father, two little baby deer, and I thought "Oh, I wish I had a gun." C ause it's right ... [L]

BA N G -BAN G -BA N G -BA N G -BA N G ! I could have just shot 'em, and killed 'em, gutted 'em, skinned 'em, sprinkled 'em on my cereal. I just had them .... [L]

so close ... to be able to ... just, no gun. I had a spoon so I could hit 'em just as hard as I ... [L]

just over their little head ... cause the baby can't run as fast. So I had that, just [L]

U ngh, ungh, ungh [sounds of intense rhythmic effort] like that. A nd it cracked. But I was just ... cause the baby is so tender and juicy, they're little, so ... [L]

A nd he just looked and scurried away, he just ... [L]

got away.

That's sarcasm. I don't understand hunting, at all. (1996 [1994]: Track 1: $1: 17 \mathrm{ff})$

In both instances, DeG eneres negates the episode by framing it as sarcasm, and each is a prelude to a bit about hunting. In the live performance, however, it is framed in the very recent and specific past (just before going on tour); M ontana is affirmed as a place of beauty through cheers; the seemingly incidental spoon returns later as a club; the clubbing interlude is not only present but fairly gruesome; and the negation, when it comes, is sotto voce. Conversely, the back-peddling of the printed version is quite elaborated and prolonged, even though it is retreating - re-establishing equilibrium - from a claim not nearly as brutal as that of the performance. DeG eneres, whose persona is nice and optimistic, plays against type to such an extent that the audience can easily make the truth/fiction judgement. Rock, on the other hand, walks a thinner line, knowing the successful black man persona still carries the perceived threatening presence of the violent black man (Bryant 2003). By building a bit around it he, in collusion with a sympathetic audience, inverts it.

In one further - and quite remarkable - display of the truth vs. fiction judgment and the control the comedian has in its execution, 
Eddie Izzard, in his 1998 concert D ress to Kill, having just finished an extended bit on Engelbert Humperdinck, informs the audience of something he has heard backstage.

But he's dead now. Did you hear that? [A w] Yeah. Today, on C N N . I heard just as I was coming out. Very weird, 'cause... Frank Sinatra was just recently as well, wasn't it? Yeah. [S->L]

Look, this is what I heard on the telly when I was coming out. [S]

$\{$ Smiling $\mathrm{N} 0$, it's not true. [L: A ]

$\{\mathrm{G}$ rave $\mathrm{No}$, it is true. [L: $\mathrm{H}$ ]

Yeah, he was in LA : something happened. He was in LA, and that's all I caught on the telly. It was just before I came out, so, yeah... [L]

\{Smiling, under breath $\}$ No. [L]

$\{G$ rave $\mathrm{N} 0$, it is true. [L]

$\mathrm{No}$, he was in a car, uh, in LA, driving along, and something hit him, or something. Something like that. [L]

$\{$ A Iternating between serious nods with raised eyebrows and smiling headshakes with dismissive hand gestures, ending on a nod.

$\mathrm{N} \mathrm{o}$, he's all right! He's all right! He's fine. H e's cooking, he's jumping, he's doing his thing in LA. H e's absolutely fine.

$\{G$ rave headshake $\}[L]\{$ Smiling nod $\}[L]$

How do I know? I don't know, I don't know. I think he's got a cold, that's what they said. [L]

N o, a tan. That's it. (1998: 1:14:40ff)

Without the theatre audience's reaction, the text is not incomprehensible per se, but at least it appears to be a seemingly random bit. The audience's confusion and inability to know what the proper response should be - largely a consequence of not having the facts at their disposal - ends up being the source of the laughter itself, not the death of H umperdinck. For the audience watching it at home, of course, the effect is different, armed with the knowledge that Humperdinck is not (or was not at the time) dead: and the uncertain reaction of the theatre audience (or the artistry I zard displays in its manipulation) is the material. John Lahr wrote about the effect on the audience of a variation of this bit:

A nd that leads him to an imitation of Dick Van Dyke's mangled Cockney in "M ary Poppins." "H e's dead, you know," I zard says about Van Dyke, bursting the bubble of laughter. Then he shakes his head. "N o, he's not." He pauses and continues, "H e is ... No ... He is ... N o." A t each volte-face, which he delivers with either a dour shake of his head or a smile, the audience's energy switches back and forth between worry and delight (2000 [1998]: 173). 


\section{True Story?}

Microphones alone cannot bring intimacy between performer and audience. The audience must also know something about the performer, locating her within their own framework. Building on the definition of routines given earlier, the comedian must interweave the comic bits in her routines with declarative statements or testimonial personal experience narratives which squarely locate her as sharing a core of fundamental precepts with her audience. M uch like the classic folkloristic formulae for what constitutes myth, these precepts are incontestable within the particular context in which they are performed and are, for lack of a better word, sacred to the group, and are met not with laughter but with applause and calls of approval. ${ }^{10}$ To provide a few examples, the following are extracts from comedians Steve H arvey and Ron James, two seemingly disparate comedians. A frican-A merican and urbane, Steve $\mathrm{H}$ arvey begins his performance first by affirming his religious conviction, then using that to address the (literally) profane nature of part of his act, and finally eliciting a sense of civic pride through narrating his negotiation with a dismissive and powerful Other:

\footnotetext{
Before I get started tonight, I'd like to say that G od is to me ...

God is everything. [C: A ]

Everything I have, and everything I am I owe to God. [A ]

N ow that I done said that, [L]

going to be some times tonight when it'll sound like I don't know

God, [L]

but I do.

Good to be here in A ugusta: it was a hard fight for me to get $\mathrm{HBO}$ to go along with coming to A ugusta. They said [C] that ...

They told me that A ugusta was too small of a town to support five thousand people for comedy, [C]

but here we are. Here we are. [C: A ] (H arvey 1997: 1:56ff)
}

Later, he alludes to the importance of the support of family and parents, with an implicit reference to his long struggle for success:

10. Rutter identifies applause unaccompanied by laughter as "practically nonexistent" in stand-up (2000: 479). I would tend to disagree with this point, although applause is certainly less commmon than laughter. He does qualify this satement, howerver by saying, "A pplause during stand-up tends to follow non-comic events. These often include events such as the put down of a persistent aggressive heckler, the announcement of a competition winner or the offering of an ideological statement" (479, emphasis mine). 
I'm the way I am because of my parents,

my mother and father are the reason I am the way I am.

$M$ y parents are very different.

M y parents are still living though: I'm grateful. [A ]

My mommy and daddy are eighty-two years old, and they're still healthy.

I'm grateful to $G$ od that my mommy and daddy lived long enough to finally see my sorry ass turn out to be just a little bit of something. (Harvey 1997: 11:33ff)

Finally, a long passage about the ultimate stupidity of racism brings a lone burst of solemn applause: it precedes, not coincidentally, a twenty minute routine (constituting one third of the performance) on the differences between blacks and whites.

You know,

sometimes when I work I try to say something of importance, you know.

I think about racism and how sick, how big of a sickness it is for our country.

I think that racism is the biggest problem we've got in this country. Some people think it's drugs and crime, [A ] but I think it's racism. I think that racism is so stupid:

I can not see disliking a person because of the colour of their skin. I only wish that people did not dislike me because of the colour of mine,

but this is A merica: that's how it goes. (Harvey 1997: 19:20ff)

Turning to the suburban Maritimer Ron James, the slow homogenisation of the N orth A merican urban landscape, with particular reference to the A mericanisation of $C$ anada, forms much of the theme of his The Road Between M y Ears show. Primarily framed around a celebration of region through the device of the perennially touring comedian, it at points occasions why one must travel to "the far points of frontier" (as he puts it elsewhere in the show) in order to experience authenticity:

O nly trouble is, when I set my compass bearing to such points somebody out there's trying to make everything in the world look the same.

W herever you go you'll see it, won't ya? T hat intersection to A nywhere, $\mathrm{N}$ orth A merica.

W hether it's on the outskirts of $\mathrm{C}$ orner Brook, N ewfoundland or Buena Vista, A rizona, 
it's that big box park of Taco Bell, Burger King, Home Depot, Wal$M$ art, G ranny Smith's, M idas M uffler, C ostco, twenty-one hundred shops at the outlet mall and

- jumpin' G erman Jesus -

how much stuff do we have to buy in order to keep this planet spinning?

[A] (James 2003: 47:30ff)

A Ithough not a political comedian in the sense of the A merican stand-ups Dennis M iller or Lewis Black, James repeatedly contrasts Canada with the U nited States. Furthermore, the tour which preceded the show began a month after the attacks on the World Trade Center and the Pentagon (a point James brings up frequently in both my interview with him and press interviews), forcing a recalibration of a general Canadian apathy or antipathy to the U nited States with a newfound sense of empathy. The audience's reaction demonstrates, two years after the events, the new worldview:

W rapping your head around 9/11 is something entirely different, isn't it, huh?

Boy, the old W estern World's spun clear off its axis since then, hasn't it?

In the event itself,

the dark gods of irony working overtime,

G eorge W. Bush falling face first into his gig at the W hite $\mathrm{H}$ ouse after the greatest electoral travesty in the history of the democratic process.

[C: A ] (James 2003: 1:05:02ff)

James' built his reputation on U p and Down in Shakeytown, a oneperson show which chronicled three years he spent in Los A ngeles after the situation comedy which prompted his move was abruptly cancelled. Both on- and offstage, he has a theme of ambivalence towards success in A merica and the de-C anadianising required to do it, as suggested by, and reaffirmed by the audience's reaction to, the following:

But, of course, you know, $C$ anada and A merica have patched up their differences now, haven't we? We're on the road to familiarity once again.

I don't think A merica's ever going to lose its mojo for Canada, is it? Unh?

A nd C anada, for A merica, especially.

Christ, every one of us would happily hop the border for a February suntan and a successful sitcom. [ $L->A$ ]

Pretty soon, what's going to pass for home-grown production in this country are half a dozen amateurs from Scarborough singing A pril W ine cover tunes on Canadian Idol. [A ] (James 2003: 1:09:13ff) 
For both Harvey and James, with their respective audiences (both the immediate live audience and, simultaneously, an intended albeit undifferentiated broadcast audience), there is a certain baseline drawn. It asserts areas of agreement, despite others of divergence, to which the audience reacts not with laughter but with indications of approval like applause or hooting. This technique works equally well for the established comedian as for the newcomer, and this establishment of common ground is often a group effort, where unknowns are introduced by hosts with an existing reputation and given some form of contextualising framework for the audience to interpret the performer and, moreover, judge the relevance of extending the trust required for intimacy. I will cite just one example. In C edric the Entertainer's Starting Line U p (Small 2002), the comedian Cedric the Entertainer (C edric Kyles) hosts an evening of new comedians. For the concert, filmed in the boxing ring of the Biloxi G rand $\mathrm{C}$ asino in Biloxi, M ississippi, C edric, having performed for fifteen minutes, makes introductions in the style of a ring announcer:

This first comedian coming to the stage

has been ripping shit up [L] all around the country, performing on the Bud Light C omedy Tour with C edric the Entertainer. He hails from Jacksonville, Florida:

weighing in at an even one hundred and thirty-five pounds soaking wet with work boots on, [L]

this brother is naturally funny. Please welcome to the stage, a member of the starting line up,

Roland Powell! Let him hear it! (15:53ff)

This next comedian,

that I'm about to bring to the stage,

hails from $\mathrm{H}$ ouston, Texas. [C]

$\mathrm{He}$ has a comedy record of numerous shows, and numerous standing ovations.

$\mathrm{He}$ is pound-for-pound one of the funniest Latinos in comedy.

Ladies and gentlemen, please welcome to the stage, Juan Villereal. (27:10ff)

I want to bring this next comedian to the stage, ladies and gentlemen. This next comedian is coming to you direct from M emphis, Tennessee. [C]

$H$ e's a smooth brother with a very quick wit. 
He's known as the brother of a thousand voices and just as many personalities.

Please put your hands together

for Tony Luewellyn! (44:17ff)

A lright, this next comedian I'm bringing to the stage,

he is a M ississippi homeboy. [C ]

Representin' the "seut, " this brother is joke-for-joke one of the funniest young comedians in the country.

$\mathrm{He}$ is a fool by nature:

he said that he did not want to have a career of shellin' peas. [L]

A II the way from Jackson, M ississippi, [C ]

y'all show some love

for J.J. (56:07ff)

In this manner, the emcee is asking the audience to extend the preexisting personal goodwill they have for him to the less well-known comedians (Rosenberg 1986: 153-157). Through the sketchiest of biographies, incorporating a presentation of generalised professional credentials, a statement of geo-social provenance, an attestation to her comedic skills, and, if necessary, an advertence to particular possible counter-expectations (such as Powell's small stature; Villereal's Latino designation in a predominantly A frican-A merican panel of performers and audience; Luewellyn's use of mimicry), the emcee contextualises the performer and the performance to come.

\section{The Making of Intimates}

Reputation is cumulative. Most stand-up comedy implies a level of performed autobiography. A t first one gives some of that biography through an explicit introduction, as in the Cedric the Entertainer examples above, but over a comedian's career some form of persona is established, mostly concerning the life lived offstage or off the road. It is one of the factors which further makes material unique to the performer and harder to transfer across repertoires. Furthermore, returning audience members bring a foreknowledge of this persona to subsequent performances, and a framework for how to interpret a specific performance is already established. The intimacy of the performance style makes intimates of the performer and audience.

M oreover, an audience has a certain investment in the life story of someone it has gotten to know through their performances. When 
famous comedians' life events spill out into the public sphere - Lenny Bruce's arrests for obscenity, Richard Pryor immolating himself while freebasing, Ellen DeG eneres' coming out, M artin Lawrence's drug fuelled rampage through the streets of Los A ngeles ${ }^{11}$ - they are often revisited on the stage. This stems in part because the virtual intimacy between performer and audience and the audience's investment in her life story implies a set of mutual rights and responsibilities; the audience is almost owed an explanation. Further, the performer must edit her autobiography, providing a version of events over which she has greater control. In effect, the comedian reframes the history as legend. Determining its truth, falsity, or mootness is no longer the purview of an indeterminate, uncontrollable public arena, but of the present audience.

Stand-up comedians are characters in their own narrative, of their own making. They profess to have had certain experiences and express certain opinions not merely in front of but to an audience. Those experiences and opinions are, again going back to Bascom's definition for legend, intended to be "regarded as true," and the audience makes a determination of the truth behind them. But legend-like testimonial statements and personal experience narratives blend with tall tales. The audience is expected to try to determine what is true and what is play. The comedian provides cues and clues, and will quickly try to establish how best to guide a particular audience towards the preferred interpretation. Her aim is not to assist them in the discernment of an actual truth, but to deliver whatever will pay off with laughter, at the time or over the course of the performance.

Stand-up comedy is occasionally looked upon and classified as our contemporary storytelling tradition (Koziski 1984: 73; Price 1998: 263; 1997: 234), and certainly some comedians on occasion invoke the moniker storyteller for themselves. ${ }^{12}$ But what is made apparent upon close inspection of the form is how much stand-up comedy depends on the audience's response. That the audience responds is both self-evident and has far-reaching consequences. A Ithough the comedian anticipates

11. These episodes are revisited in, respectively, Bruce 1992 [1966], Pryor 1982, DeG eneres 2000, and Lawrence 2002.

12. For an example of a comedian, see R on James as quoted in Pedersen 2001: "A microphone, you, a glass of water on a stool - it feel s old, like standing around a campfire on the veldt, telling stories" ( B 15). However, see him also as 
and plans for this response, its specific form can never be assured. That response is what makes the text so very elusive and odd when transcribed, and why so much reworking even by the comedians themselves needs to be done for the stand-up routine to begin to resemble something presentable, let alone funny when they put it on the page. Despite the power of performance ultimately residing with the performer, stand-up comedy is a genre predicated on having someone beyond the performer interpret, develop and shape it as it progresses, which makes it distinct among professional solo performance genres.

quoted in Cole 2005: "There is just one thing; don't call him a storyteller. 'W hen I think of a storyteller, I think of an old folkie, over by a puppet theatre at a folk festival. I don't think a storyteller would have been able to get three 90-minute specials on major $\mathrm{C}$ anadian networks. I see myself as a comedian who tells funny stories'" ( $\left.\begin{array}{ll}\text { C } & 1\end{array}\right)$. 


\section{References}

A ugestad, Kate. 2004. "M usic Technology and Vocal Performance."

Paper presented at $\mathrm{New}$ Media Conference: $\mathrm{N}$ ew M edia as

Culture Techniques and as Fora for Communicative A ction.

Bergen, N orway, $28 \mathrm{M}$ ay. A vailable at Kulturteknikker. http://

www.kulturteknikker.hivolda.nodefault.asp?kat $=655 \&$ id $=2440 \& \mathrm{sp}=1$.

A ccessed 4 February 2008.

Bakhtin, M.M. 1981. The Dialogic Imagination: Four Essays. M ichael

Holquist, ed. A ustin: University of Texas Press.

Bascom, W illiam. 1954. "Four Functions of Folklore." Journal of A merican Folklore 67(266): 333-349.

- - . 1965. "The Forms of Folklore: Prose Narratives." Journal of

A merican Folklore 78 (307): 3-19.

Bergson, H enri. 1900. Le Rire: Essai sur la signification du comique. Paris: A Ican.

Bruce, Lenny. 1992 [1966]. The Lenny Bruce Performance Film. Dir. John M agnusson. VHS and CD. Rhino Home Video.

Bryant, Jerry H. 2003. "Born in a M ighty Bad Land": The V iolent $M$ an in A frican-A merican Folklore and Fiction. Bloomington and Indianapolis: Indiana U niversity Press.

Butler, G ary. 1991. Saying Isn't Believing: Conversation, N arrative and the $D$ iscourse of Belief in a F rench- $N$ ewfoundland $C$ ommunity. St. John's: Institute of Social and Economic Research. (Publications of the A merican Folklore Society [PA FS], N ew Series.)

Carlin, George. 1997. G eorge Carlin: 40 Years of Comedy. Cable television recording. $\mathrm{HBO}$.

Cole, Sally. 2005. "Canadians keeping their sense of humour." The G uardian ( C harlottetown), 11 N ovember: C 1.

Dargan, A manda and Steven Zeitlin. 1983. "A merican Talkers:

Expressive Styles and Occupational Choice." Journal of A merican Folklore 96(379): 3-33.

Davies, Christie. 1990. Ethnic H umor A round the World: A Comparative A nalysis. Indianapolis and Bloomington: Indiana U niversity Press. DeG eneres, Ellen. 1995. M y Point... A nd I Do H ave $\mathrm{O}$ ne. N ew York: Bantam.

- - - 1996 [1994]. Taste T his. CD. A tlantic.

- - - 2000. Ellen DeG eneres: The Beginning. Cable television recording. $\mathrm{HBO}$. 
Dégh, Linda. 2001. Legend and Belief: D ialectics of a Folklore Genre.

Bloomington and Indianapolis: Indiana U niversity Press.

Dundes, A lan. 1964. "Texture, Text, and Context." Southern Folklore Q uarterly 28(4): 251-265.

Ellis, Bill. 2001. A liens, G hosts and C ults: Legends W e Live. Jackson, M S:

U niversity of $\mathrm{M}$ ississippi Press.

Freud, Sigmund. 1976 [1905]. Jokes and their Relation to the U nconscious.

Trans. James Strachey. Penguin Freud Library 6. London: Penguin. Frith, Simon. 1996. Performing Rites: On the Value of Popular M usic.

Cambridge, M A : H arvard U niversity Press.

Fulton, DoVeanna S. 2004. "C omic Views and M etaphysical Dilemmas:

Shattering Cultural Images Through Self-Definition and

Representation by Black C omediennes." Journal of A merican Folklore 117(463): 81-96.

Georges, Robert A. 1969. "Toward an Understanding of Storytelling

Events." Journal of A merican Folklore 82(326): 313-328.

G offman, Erving. 1959. The Presentation of Self in Everyday Life. Garden

City: A nchor Books.

H arvey, Steve. 2001 [1997]. O ne M an. Dir. Chuck Vinson. DVD.

U rbanW orks Entertainment.

Henken, Elissa. 2006. "G enre Selection: Legend or Joke." Paper

presented at the A nnual $G$ eneral M eeting of the A merican Folklore Society, M ilwaukee W I.

James, Ron. 2003. The Road B etween M y Ears. Prod. Harold Rosen.

DV D. M orningstar Entertainment/C BC Home Video.

Koziski, Stephanie. 1984. "T he Standup Comedian as A nthropologist:

Intentional Culture C ritic." Journal of Popular Culture 18(2): 5776.

Lahr, John. 2000 [1998]. "Eddie Izzard: The Izzard King." In Show and

Tell: N ew Yorker Profiles: 171-182. Woodstock and N ew York:

O verlook Press.

Lawrence, M artin. 2002. M artin Lawrence Live: Runteldat. Concert film.

M TV Films.

Limon, John. 2000. Stand-U p C omedy in Theory, or, A bjection in A merica.

Durham and London: Duke U niversity Press.

Lockheart, Paula. 2003. "A H istory of Early M icrophone Singing, 1925-

1939: A merican Mainstream Popular Singing at the A dvent of Electronic Microphone A mplification." Popular M usic and Society 26(3): 367-385. 
Lonergan, Bernard. 1957. Insight. London: Darton Longman and Todd. M cC racken, A llison. 1999. "'G od's G ift to U s G irls': C rooning, G ender, and the Re-Creation of A merican Popular Song, 1928-1933." A merican M usic 17(4): 365-395.

M intz, Lawrence E. 1998. "Stand-up Comedy as Social and Cultural Mediation." In Nancy A. Walker ed., W hat's So Funny?: H umor in A merican C ulture: 193-204. Wilmington: Scholarly Resources. M urphy, Eddie. 1983. Delirious. Cable television recording. HBO. N arváez, Peter. 1984. "Folksong." In Joseph R. Smallwood ed.,

Encyclopedia of $\mathrm{N}$ ewfoundland. Vol. 2: 249-52. St. John's: N ewfoundland Book Publishers.

- - - . 1986. "Joseph R. Smallwood, 'T he Barrelman': The Broadcaster as Folklorist." [1983] In N arváez and M artin Laba eds., M edia Sense: The Folklore-Popular $C$ ulture $C$ ontinuum:47-64. Bowling $\mathrm{G}$ reen, $\mathrm{OH}$ : Bowling Green State U niversity Popular Press.

- - - . 1995. "N ewfoundland Vernacular Song." In W ill Straw, Stacey Johnson, Rebecca Sullivan and Paul Friedlander eds., Popular M usic: Style and Identity: 215-19. Montréal, Q uébec: The Centre for Research on Canadian Cultural Industries and Institutions.

- - - 2001. "Unplugged: Blues Guitarists and the $M$ yth of A cousticity." In A ndy Bennett and Kevin Dawe eds., G uitar $C$ ultures: 27-44. Oxford: Berg.

- - - ed. 2003. Of C orpse: D eath and Humor in Folklore and Popular Culture. Logan: U tah State University Press.

- - - and Martin Laba. 1986. "The Folklore-Popular Culture Continuum." Introduction. In N arváez and M artin Laba eds., M edia Sense: T he Folklore-Popular C ulture C ontinuum: 1-8. Bowling G reen, $\mathrm{OH}$ : Bowling $\mathrm{G}$ reen State U niversity Popular Press.

0 'M eally, Robert. 1991. Lady Day: The M any Faces of Billie Holiday. $\mathrm{N}$ ew York: A rcade.

O ring, Elliott. 1992. Jokes and Their Relations. Lexington: U niversity Press of Kentucky.

Pedersen, Stephen. 2001. "James Serious A bout Stand-up: Comedian Brings N ew Show to N.S." The Chronicle-H erald (H alifax), 6 N ovember: B15.

Price, Darby Li Po. 1998. "Laughing without Reservation: Indian Standup Comedians." A merican Indian C ulture and Research Journal 22(4): 255-71.

Pryor, Richard. 1982. Richard Pryor Live on the Sunset Strip. Concert film. Columbia Pictures. 
Rock, Chris. 1994. "Big A ss Jokes." H BO Comedy Half Hour. Cable television recording. $\mathrm{HBO}$.

- - . 1997. Rock This! N ew York: Diane.

Rosenberg, N eil V. 1986. "Big Fish, Small Pond. Country M usicians and Their M arkets." In N arváez and M artin Laba eds., M edia Sense:

The Folklore-Popular C ulture C ontinuum: 149-166. Bowling G reen,

$\mathrm{OH}$ : Bowling G reen State U niversity Popular Press.

Rutter, Jason. 2000. "The Stand-up Introduction Sequence: Comparing Comedy Compères." J ournal of Pragmatics 32: 463-483.

Shuker, R oy. 2001. U nderstanding Popular M usic. London and N ew York: R outledge.

Small, Leslie, dir. 2002. C edric the Entertainer's Starting Line U p. DVD. U rbanW orks Entertainment.

Stone, Kay. 1997. "Social Identity in Organized Storytelling." W estern Folklore 56(3/4): 233-241.

Szwed, John. 2002. So W hat: T he Life of M iles Davis. N ew York: Simon $\&$ Schuster.

Thomas, Jeannie B. 1997. "Dumb Blondes, Dan Quayle, and Hillary Clinton: Gender, Sexuality, and Stupidity in Jokes." Journal of A merican Folklore 110(437): 277-313.

W ong, Deborah. 1994. "'I W ant the M icrophone': M ass Mediation and A gency in A sian-A merican Popular M usic." TDR 38.3: 152-167. W right, Steven D. 1999. "Ben Elton." Best of B ritish. Television program. $B B C$.

Zolten, J. Jerome. 1993. "Black Comedians: Forging an Ethnic Image." Journal of A merican Culture 16(2): 65-75. 